\title{
REVIEW
}

\section{Nitric oxide: NO apoptosis or turning it ON?}

\author{
Bernhard Brüne ${ }^{\star, 1}$ \\ ${ }^{1}$ University of Kaiserslautern, Faculty of Biology, Department of Cell Biology, \\ 67663 Kaiserslautern, Germany \\ * Corresponding author: B Brüne; Tel: +49-631-205 2406; \\ Fax: +49-631-205 2492; E-mail: bruene@ @rhrk.uni-kl.de
}

Received 13.3.03; accepted 19.3.03

Edited by G Melino

\begin{abstract}
Nitric oxide (NO) is known for its diverse activities throughout biology. Among signaling qualities, NO affects cellular decisions of life and death either by turning on apoptotic pathways or by shutting them off. Although copious reports support both notions, the dichotomy of NO actions remains unsolved. Proapoptotic pathways of NO are compatible with established signaling circuits appreciated for mitochondriadependent roads of death, with some emphasis on the involvement of the tumor suppressor p53 as a target during cell death execution. Antiapoptotic actions of NO are numerous, ranging from an immediate interference with proapoptotic signaling cascades to long-lasting effects based on expression of cell protective proteins with some interest on the ability of NO-redox species to block caspases by Snitrosylation/S-nitrosation. Summarizing emerging concepts to understand p53 accumulation on the one hand while proposing inhibition of procaspase processing on the other may help to define the pro- versus antiapoptotic roles of NO. Cell Death and Differentiation (2003) 10, 864-869. doi:10.1038/ sj.cdd. 4401261
\end{abstract}

Keywords: nitric oxide-related species; apoptosis; necrosis; cell protection; p53; caspases

Abbreviations: NO, nitric oxide; NOS, nitric oxide synthase; iNOS, inducible NOS; RNI, reactive nitrogen intermediates; ROI, reactive oxygen intermediates; Mdm2, murine double minute; CHOP, C/EBP homologous protein (also known as GADD153); MAPK, mitogen activated protein kinases; DISC, death inducing signaling complex; CARD, caspase recruitment domain; Apaf, apoptosis protease activating factor 1 .

\section{Introduction}

Nitric oxide (NO) taught us to revise traditional thinking and to incorporate new concepts of cellular communication that previously had been excluded from our pictures of biology/ medicine. It was somewhat unexpected that a small molecule being a gas was identified as the endothelium-derived relaxing factor (EDRF) ${ }^{1,2}$ and became a powerful intra- and intercellular messenger that touches nearly all areas of life. Endogenous NO is synthesized from L-arginine by a family of nitric oxide synthase (NOS) isoenzymes, and it is becoming evident that NOS activity is associated with human diseases and disorders. ${ }^{3,4} \mathrm{NO}$ formation under inflammatory conditions influences gene expression, affects the relationship between mammalian hosts and microbial pathogens, modulates immune responses and can contribute to cell demise by affecting apoptosis.

In the past, radicals had been associated with pathophysiology; now it is being appreciated that NO is a molecule with important signaling qualities. Biological actions can often be attributed to 'reactive nitrogen intermediates' (RNI) rather than NO itself. The term RNI refers to oxidation states and adducts of the products of NOS, ranging from nitric oxide $(\cdot \mathrm{NO})$ to nitrate $\left(\mathrm{NO}_{3}^{-}\right)$in some analogy to reactive oxygen intermediates(ROI) that encompass intermediate products when oxygen is reduced to water. It is clear that biologically significant NO redox and additive reactions include those with $\mathrm{ROI}$ and transition metals that in turn dictate NO chemistry. ${ }^{5-7}$ In particular, $\mathrm{NO}^{+}$is a redox species with the ability to undergo addition or substitution reactions with nucleophiles, among others sulfur, resulting in -S-NO ( $S$-nitrosothiol) formation. Under cellular conditions, rather $\mathrm{NO}^{+}$carrier species such as $\mathrm{N}_{2} \mathrm{O}_{3}$, or an $\mathrm{N}_{2} \mathrm{O}_{3}$-like species as well as a Fenton-type reaction may account for protein nitrosation. ${ }^{8-10} S$-nitrosothiol formation is reversible and considered the phenotypic redoxbased NO-signaling mechanism. ${ }^{11}$ These signaling pathways are cGMP-independent and appear to predominate in facilitating cytostatic, cytotoxic or protective NO effects. However, the 'classic' signaling behavior of NO, which is attributed to soluble guanylyl cyclase activation, ${ }^{12}$ can not be neglected to explain pro- or antiapoptotic roles of NO.

Apoptosis, or programmed cell death, is a major form of cell death characterized by a series of stereotypic morphological and biochemical features. ${ }^{13}$ To understand the role of NO, we should recapitulate that death pathways can be divided into two components, either involving mitochondria or death receptors. Death receptor activation attracts and activates procaspase-8 through interactions between the death effector domains of these two proteins. In the mitochondrial pathway, cytochrome $\mathrm{c}$ is released to associate in an ATP- or dATPdependent manner with apoptosis protease activating factor 1 (Apaf-1) to form a multimeric complex, known as the apoptosome, that recruits and activates procaspase-9. This is followed by activation of executioner caspases such as caspase-3 or -7 . Thus, in death receptor-mediated apoptosis caspase- 8 is the most apical caspase, whereas in the mitochondrial pathway this position is taken by caspase- 9 .

First indications on NO-evoked apoptosis appeared in 1993. ${ }^{14,15}$ Since then apoptosis by NO has been shown and is still being noticed in many different primary or immortalized 
murine or human cells. ${ }^{16-18}$ Apparently, the threshold for a proapoptotic triggering event of $\mathrm{NO}$ varies considerably from one cell to another, but allows one to conclude that NO uses the mitochondrial subroute leading to cell death. Mitochondria comprise a target for $\mathrm{NO}$ and there is accumulating evidence that inhibition of respiration may contribute to the proapoptotic effect of $\mathrm{NO}$ by membrane potential reduction, transition pore opening and release of cytochrome $c .^{19,20}$ In a cell free system containing mitochondria and nuclei, NO induced mitochondrial permeability transition and promotes apoptosis which was attenuated by permeability transition inhibitors. ${ }^{21}$ In macrophages, nitrosothiol-evoked apoptosis is blocked by preventing mitochondrial permeability transition pore opening $^{22}$ while in neuronal cells an intracellular mitochondriaderived calcium increase, which is attenuated by cyclosporin A, may contribute to excitotoxicity. ${ }^{23}$

There is consolidation that a caspase-3-like group (caspase-3 and -7), caspase-2 and caspase-9 are central components in a cascade triggered by NO. ${ }^{24,25}$ Importantly, Western blot analysis confirmed the processing of caspases, with the further notion that blocking mitochondrial permeability transition attenuated caspase activation. ${ }^{26}$ The importance of the cellular redox balance in caspase activation was demonstrated by the finding that NO-elicited caspase activation was largely attenuated by incubating cells with iron sulfate to increase the intracellular iron content and thus to affect the chemical fate of $\mathrm{NO}^{27}$ Observing caspase activation under the influence of NO should not be considered as a direct impact on the zymogen-active caspase transition, but rather an indirect effect as a result of NO-evoked signal transmission.

\section{NO evoked accumulation of p53}

In 1994 it became apparent that NO, generated either via inducible NOS (iNOS) or the breakdown of NO donors, evoked p53 accumulation in murine macrophages. ${ }^{28}$ However, accumulation of p53 should not be taken as a proof that DNA damage is involved because NO generated DNA damage only inefficient at the cellular level. ${ }^{29,30}$ Supporting evidence for the link between $\mathrm{NO}$ and p53 came from observations that macrophages derived from iNOS ${ }^{-1-}$ animals failed to demonstrate nuclear p53 localization after in vivo bleomycin exposure. ${ }^{31}$ There is some agreement that p53 is transcriptionally active based on observations that p53 is needed for NO to upregulate cell cycle regulators or proapoptotic proteins such as p21(Waf1/Cip1) or Bax ${ }^{32,33}$ with the further notion that Akt attenuated p53-dependent transcriptional activation and suppressed NO-elicited cell death. ${ }^{34}$ Experiments in thymocytes from p53-null mice or in mutant p53 human lymphoblastoid cells revealed that these cells were resistant or less sensitive to NO-induced apoptosis, underscoring the notion that p53 may transmit a proapoptotic NO-response. ${ }^{35,36}$ Accumulated p53 reveals phosphorylation at distinct residues with serine 15 being the most prominent. ${ }^{37,38}$ This is in line with current concepts proposing posttranslational modification of $\mathrm{p} 53$ at either the $\mathrm{N}$ - or $\mathrm{C}$-terminus to affect stability regulation in general, with serine 15 phosphorylation being a prerequisite for the transcriptional activity of p53 in particular. Studies with p53 N-terminal mutations at serines $15,20,33$ or 37 indicated multiple and functionally overlapping phosphorylation sites to control p53 activity. Advancing studies reported that NO neither uses ataxia telangiectasia-mutated (ATM) nor the alternate reading frame (ARF) tumor suppressor protein to accumulate $p 53 .^{39}$ However, these findings were recently questioned by demonstrating that phosphorylation of p53 at serine 15 is ATM and ATM- and Rad3- related (ATR)-dependent but p38- and DNA$P K$-independent based on studies in isogenic human cell lines and MEFs from gene knockout $\left(\mathrm{ATM}^{-1-}\right)$ mice, although mechanisms of ATM/ATR activation by $\mathrm{NO}$ remained unknown. ${ }^{40}$ In addition, a transient and reversible downregulation of $\mathrm{Mdm} 2$ by $\mathrm{NO}$ is claimed to contribute to the activation of $\mathrm{p} 53 .^{39}$ More recent studies confirmed p53 stabilization under the impact of $\mathrm{NO}$, accumulation of a transcriptionally active, serine 15-phosphorylated p53, with predominant nuclear localization. ${ }^{41}$ However, stabilized p53, which is phosphorylated at serine 15 , still bound its negative regulator Mdm2 and Mdm2-evoked polyubiquitination of p53 remained intact. Cell fractioning and heterokaryon analysis suggested that $\mathrm{NO}$, in some analogy to leptomycin B, prevents nuclear-cytoplasmic shuttling of p53, which may result in nuclear protein stabilization/activation. Phosphorylation of p53 not only affects transcriptional activation of p53 but is also considered a master regulator of p53/Mdm2 complex formation. Based on in vitro experiments, it is predicted that phosphorylation of p53 at serine 15 is incompatible with p53/ Mdm2 interactions, thus facilitating protein dissociation with concomitant p53 stabilization. ${ }^{42}$ However, based on luciferase assay and in vitro interaction studies, Dumaz and Meek $^{43}$ noticed that serine 15 modification of p53 alone did not dissociate p53 from Mdm2, although modification of serine 15 stimulates the transcriptional activity of the tumor suppressor. This situation is reflected when NO treatment of NIH 3T3 fibroblasts or human RKO cells left the p53/Mdm2 complex formation intact, allowed serine 15 phosphorylation of p53 and provoked p53-luciferase activity. ${ }^{41}$ Compatible with an intact p53/Mdm2 interaction is an unaltered ubiquitination pattern of either exogenous HA-tagged or endogenous p53 under NO treatment. The recent report that an initial, however transient, drop in Mdm2 accounts for early accumulation of p53 in response to $\mathrm{NO}$, whereas in a second phase p53 remained stabilized although Mdm2 increases above controls because of transactivation of the mdm2 gene, ${ }^{39}$ is consistent with showing increased Mdm2 expression and p53 stabilization under long lasting NO exposure. Whereas Wang et al. ${ }^{39}$ noted difficulties in explaining p53 accumulation under conditions of elevated Mdm2 expression, nuclear trapping of p53 may offer an explanation. Heterokaryon analysis indeed provided evidence that NO attenuated nuclear-cytoplasmic shuttling of serine 15 phosphorylated p53. Serine 15-phosphorylation has been correlated with attenuated nuclear export, and it remains to be established whether this striking correlation accounts for a cause-effect relation. ${ }^{44}$ Figure 1 provides a schematic description of p53 accumulation under the impact of NO.

Leptomycin B, an established blocker of p53 nuclear export, targets an active cysteine residue in CRM1 (chromosome region maintenance 1 ), which blocks formation of the export 


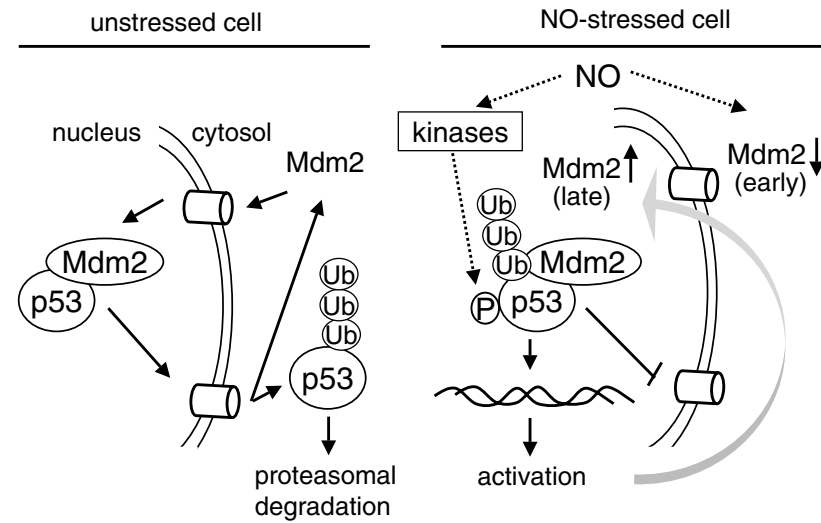

Figure 1 p53 accumulation in NO-stressed cells. In unstressed cells, p53 and Mdm2 shuttle between the nucleus and the cytoplasm with 26S-proteasomal degradation of p53. In NO-stressed cells, p53 is trapped in the nucleus, is phosphorylated, ubiquitinated and transcriptionally active. During the early phase of NO-treatment Mdm2 is downregulated whereas its expression is upregulated at later time points. Multiple kinases may (in)directly contribute to phosphorylation of p53. For details see text.

protein complex. A similar mechanism may apply for $\mathrm{NO}$ as well, considering the ability of NO-redox species to nitrosylate thiol groups. Results on nuclear trapping of p53 are consistent with the findings by M Oren that NO can increase the nuclear import and retention of p53 in neuroblastoma cell lines in which p53 is cytoplasmatic. ${ }^{45}$ Phosphorylation and transactivation of $p 53$ were also identified in cells cocultured with NOreleasing macrophages and in ulcerative colitis where iNOS expression positively correlated with $\mathrm{p} 53$ serine 15 phosphorylation. This highlights a role of $\mathrm{NO}$ in the induction of cellular stress and activation of a p53 response pathway during chronic inflammation. ${ }^{40}$

There is some interest in the ability of NO to activate kinases in general and to correlate this to cell survival decisions. NO activates all members of the MAPK pathway such as JNK (c-Jun N-terminal kinase), p38-kinase and ERK1/2 (extracellular regulated kinases). ${ }^{46} \mathrm{~A}$ gross simplification implies that p38 and/or JNK activation conveys a proapoptotic NO signal that will provoke p53 accumulation, caspase activation and cell dissolution. ${ }^{47-52}$ Besides, protein kinase C modulates NO-elicited cell death. ${ }^{53,54}$ Unfortunately, inhibition of $\mathrm{PKC}$ is either correlated with attenuated apoptosis or its enhancement, including p53 accumulation, in the case of $\mathrm{PKC} \alpha$ or $\mathrm{PKC}-\zeta$ inhibition, while PKC- $\varepsilon$ may promote NOinduced damage to colonic mucosal cells. ${ }^{55}$ One may conclude that kinases represent an attractive target for NO that allows one to initiate a proapoptotic signal and to contribute to phosphorylation and/or activation of p53. However, signaling networks make it difficult, if not impossible, to predict causation and to unequivocally position distinct kinases or phosphoproteins in the apoptotic cascade. Furthermore, molecular mechanisms of kinase activation by $\mathrm{NO}$ need clarification. Accumulation of $\mathrm{p} 53$ by NO allows one to add NO to an established list of proapoptotic and/or cellcycle regulatory compounds.

Considering that the p53 response is not eminent in all cells, alternative pathways may operate. One suggestion is the expression of CHOP (also known as GADD153; growth arrest and DNA-damage inducible gene), a transcription factor known to respond to endoplasmic reticulum stress. ${ }^{29,56,57}$ CHOP induction preceded cytochrome $c$ release from mitochondria and NO-evoked apoptosis was prevented by a CHOP dominant negative form. This pathway may account for p53-independent routes of cell death.

\section{The NO-caspase connection in cell survival}

The antiapoptotic role of NO has been addressed in several comprehensive review articles ${ }^{16,18,19,58,59}$ covering essential mechanisms such as protection via cGMP, cell death protective protein expression or radical-radical interferences. Some interest centered around caspase inhibition by $\mathrm{NO}$ as a mechanism to block cell death. With new information emerging, we may revise initial concepts on S-nitrosation of active caspases with the view that NO may attenuate caspase processing.

There is unquestionable evidence that the active site of caspases can be S-nitrosated in cell free studies, which results in loss of enzyme function, while activity can be regained by an excess of reducing equivalents. ${ }^{8,60}$ From first reports in $1997^{61-68}$ and many corroborating studies, it appeared highly attractive to propose that NO, while targeting the reactive cysteine residue inherent to all caspase-family members, would block apoptosis. However, from the very beginning, it was and still is difficult to explain these results in light of caspase activation in association with the proapoptotic role of NO. While many studies noticed attenuated, that is, mostly caspase-3, activity under the impact of NO, only a few examinations paid attention to the question of whether caspases actually had been cleaved and inactivation indeed resulted from post-translational modification of the active site cysteine, ${ }^{69}$ or whether NO impaired critical steps in a pathway leading to caspase activation. Conceptionally, it is important to note that not seeing caspase activity does not necessarily imply S-nitrosation of a caspase, although this type of modification does exist, as seen with purified proteins or in a cell free system. Based on in vitro examinations, inhibition of caspases was reversible with DTT and cleavage of S-NO bonds with $\mathrm{Hg}^{2+}$ followed by the subsequent determination of nitrite/nitrate as NO-oxidation products, implied S-nitosation. ${ }^{69}$ As expected, all caspase family members showed a similar behavior, with some variations in the amount of NO being incorporated, which ranged from 1 to 2 mol NO per mole of caspase. When analyzing S-nitrosation of caspase-3 by electrospray ionization mass spectrometry (ESI-MS), multiple relative mass increases of $30 \pm 1 \mathrm{Da}$ in both the $\mathrm{p} 12$ (small) and p17 (large) subunits of caspase-3 were detected, indicating single to triple S-nitrosation (poly S-nitrosation) of caspase-3. ${ }^{70}$ In addition, a significant portion of unmodified protein was enzymatically inactive, most likely caused by in vitro oxidation of critical thiols. One may conclude that (i) calculating the amount of S-NO bonds needs to consider any contribution of poly S-nitrosation recalculated to the amount of unmodified and/or oxidized thiol groups and (ii) S-nitrosation and other thiol modifications may occur simultaneously at the 
same protein. Along that line, S-nitroso bonds can be cleaved with release of $\mathrm{NO}$ and partial formation of protein mixed disulfides with glutathione, detected by a relative mass increase of $306 \mathrm{Da}$. This is in line with observations on the modification of transcription factors such as AP-1 where NOinduced S-glutathionylation, which occurs under reductive conditions (GSH/GSSG ratios >100), involves intermediate formation of S-nitrosoglutathione. ${ }^{71}$

It comes to the important question of whether changes seen in vitro are reflected under more complex, that is, cellular, conditions. Assuming that NO attenuates active caspases by S-nitrosation or oxidation in intact cells, one would assume that enzyme activity can be restored in vitro (breaking up the cells, measuring caspase activity in the cytosol) by an excess of DTT. However, this is not the case, or was only marginally effective. ${ }^{27}$ Unfortunately, an essential control experiment, that is, dithiothreitol reversibility in combination with Western analysis of cleaved versus noncleaved caspases, is missing in many studies that dealt with inhibition of caspase activity under NO delivery, and many authors may have imprecisely used the term caspase inhibition for conditions when caspases have not been properly processed. In some cells (e.g. human Jurkat cells) NO blocked apoptosis and caspases are not being processed to their active form. This implies that NO interferes at some point in the proapoptotic-signaling cascade by not allowing processing, that is, activation, of caspases instead of interfering directly and thus blocking enzyme activity. ${ }^{72}$ Whether S-nitrosation of procaspases, which has recently been demonstrated for caspase-9, is involved or whether assembly of the apoptosome is attenuated remains to be shown. ${ }^{73}$ The emerging picture of blocking caspase processing instead of directly interfering with enzyme activity is in line with observations that oxidative stress transiently reduces caspase activity only after the enzymes were activated whereas oxidative stress was not inhibitory for unprocessed caspases. ${ }^{74,75}$ Experiments in Jurkat cells suggest that $\mathrm{NO}$ attenuates apoptosis by inhibiting the Apaf$1 /$ caspase- 9 apoptosome assembly and promoted formation of the inactive $\sim 1.4 \mathrm{MDa}$ apoptosome complex, rather than the active $\sim 700 \mathrm{kDa}$ complex. ${ }^{72}$ Confirming inhibition of caspases in Fas-stimulated cells as a result of NO addition, it was surprising, however, that DTT did not restore caspase activity, ruling out S-nitrosation or oxidation as the sole underlying inhibitory mechanism. Western analysis indicated instead that NO inhibited the processing/activation of caspase-9, in addition to inhibiting the activity of some processed caspase-3. In hepatocytes, SNAP was reported to suppress the processing of caspase-8 in response to TNF- $\alpha$ /actinomycin D. ${ }^{76}$ However, given that hepatocytes are type II cells, it is unclear whether NO inhibited receptor-mediated activation of caspase-8 at the DISC or caspase-3-mediated processing of caspase-8, downstream of cytochrome $c$ release and activation of the apoptosome. Examinations in different cells showed that NO treatment still allowed cytochrome $c$ release although capase 3 was not activated, which pointed to some interference of NO downstream of mitochondria. ${ }^{27,72,77}$ Results from the Apaf-1/caspase-9 coprecipitation, GST pull-down, and Apaf-1 oligomerization assays suggest that NO may affect the recruitment of caspase- 9 to the apoptosome complex by indirectly interfering with CARD-CARD

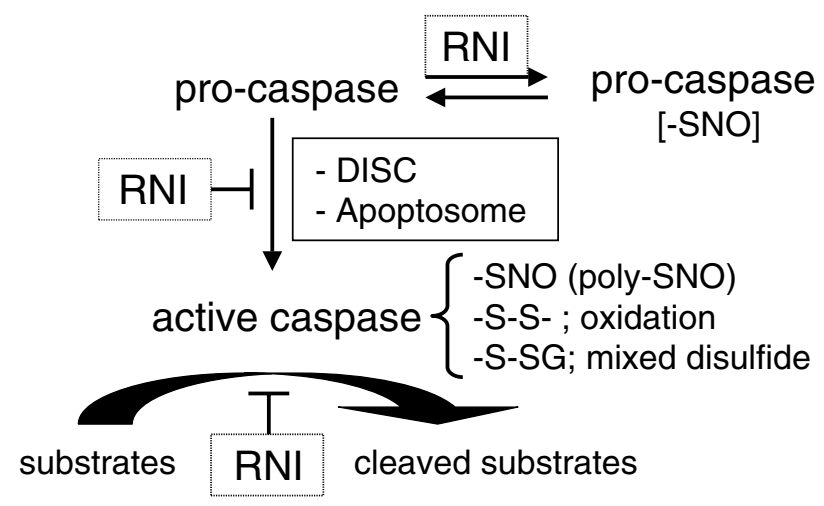

Figure 2 Caspase modulation/post-translational modification under the impact of NO. RNI may promote reversible S-nitrosylation/-nitrosation (-SNO) of pro caspases with denitrosation predominating under cell, that is, Fas-activation. RNI may indirectly block processing of caspases at the DISC or the apoptosome which attenuates the procaspases - active caspase conversion. Once an active enzyme is produced, it is subjected to (poly)-S-nitrosation, intramolecular oxidation (-S-S-) or mixed disulfide formation (-S-SG), all of which may attenuate caspase activity and thereby block substrate cleavage

interactions. ${ }^{72}$ Considering that the apoptosome assembly, in general, and CARD/CARD interactions, in particular, are proposed targets for antiapoptotic heat-shock proteins, it is interesting that NO appears to function in a similar way. ${ }^{78,79}$ Basic consideration of caspase modification/post-translational modification are summarized in Figure 2. Apoptosome assembly and DISC formation possess similar features, ${ }^{80}$ and thus NO could potentially interfere with caspase activation at both sites.

It can be concluded that inhibition of apoptosis as a result of $\mathrm{NO}$ generation is mechanistically not restricted to S-nitrosylation of active caspases, rather being compatible with limited caspase processing. In the case of caspase-3 or caspase-9, modification of proenzymes by $\mathrm{NO}$ has been demonstrated. ${ }^{73,77}$ Considering that Fas induces caspase denitrosylation, ${ }^{73}$ it appears unlikely that procaspase S-nitrosylation accounts for an attenuated caspase response seen under the impact of NO. Attenuating caspase processing rather than blocking caspase activity may resolve some of the controversy on $\mathrm{NO}$ in promoting or antagonizing caspase activity. Assuming that apoptosome and/or DISC formation with subsequent caspase processing is subjected to regulation by multiple proteins in a cell-type-specific manner allows one to rationalize a negative impact of $\mathrm{NO}$ in some, but not all cells, depending on the expression of these regulatory proteins. This may allow one to understand caspase activation under the impact of NO if caspase processing rather than caspase activity is subjected to the sphere of NO action.

\section{Concluding remarks}

Unfortunately, there is no simple answer on our picture of NO in affecting cell death. In some cases NO turns apoptosis 'on', but in other cases there in 'no' apoptosis with NO. It is accepted that $\mathrm{RNI}$ are produced in both nontoxic (signaling) and toxic formats and signaling qualities of $\mathrm{NO}$ as a direct 
effector and regulator of other denominators emerged. This allows one to rationalize individual pro- or antiapoptotic actions, but fails to delivery a unifying and predictive concept on NO signaling. Regulation of apoptosis occurs at multiple levels in three-dimensional signal transduction pathways and many different incoming signals as well as intracellular set points regulate the initiation of apoptosis or its inhibition. This complexity is cell specific and determines the reactivity towards NO. It can be predicted that our knowledge on the role of NO in affecting cell demise will substantially increase when we understand how an NO-sensitive cell can be shifted towards an insensitive one and vice versa. The plethora of variables and the inherent complexity of NO biology hinder present efforts to define a simple role of $\mathrm{NO}$ in apoptosis. Along the road new information will appear and refine current concepts on p53 accumulation and caspase processing, and at the very end (nobody knows when it will be) we hopefully will answer the precise role of NO in cell survival decisions.

\section{Acknowledgements}

I apologize to researchers whose primary observations that form the basis for our current knowledge in this active field could not be cited because of space limitations. Our work was supported by grants from Deutsche Forschungsgemeinschaft (Br 999), Deutsche Krebshilfe, Sander Foundation and Fonds der Chemischen Industrie.

\section{References}

1. Ignarro LJ, Byrns RE, Buga GM and Wood KS (1987) Endothelium-derived relaxing factor from pulmonary artery and vein possesses pharmacologic and chemical properties identical to those of nitric oxide radical. Circ. Res. 61: 866879

2. Palmer RM, Ferrige AG and Moncada S (1987) Nitric oxide release accounts for the biological activity of endothelium-derived relaxing factor. Nature 327 : 524-526

3. Kroncke KD, Suschek CV and Kolb-Bachofen V (2000) Implications of inducible nitric oxide synthase expression and enzyme activity. Antioxid. Redox Signal 2: 585-605

4. Kaufman PL (1999) Nitric-oxide synthase and neurodegeneration/ neuroprotection. Proc. Natl. Acad. Sci. USA 96: 9455-9456

5. Grisham MB, Jourd'Heuil D and Wink DA (1999) Nitric oxide. I. Physiological chemistry of nitric oxide and its metabolites:implications in inflammation. Am. J. Physiol. 276: G315-G321

6. Fukuto JM (1995) Chemistry of nitric oxide: biologically relevant aspects. Adv. Pharmacol. 34: 1-15

7. Stamler JS (1994) Redox signaling: nitrosylation and related target interactions of nitric oxide. Cell 78: 931-936

8. Daiber A, Frein D, Namgaladze D and Ullrich V (2002) Oxidation and nitrosation in the nitrogen monoxide/superoxide system. J. Biol. Chem. 277: $11882-11888$

9. Espey MG, Thomas DD, Miranda KM and Wink DA (2002) Focusing of nitric oxide mediated nitrosation and oxidative nitrosylation as a consequence of reaction with superoxide. Proc. Natl. Acad. Sci. USA 99: 11127-11132

10. Thomas DD, Espey MG, Vitek MP, Miranda KM and Wink DA (2002) Protein nitration is mediated by heme and free metals through Fenton-type chemistry: an alternative to the NO/O2- reaction. Proc. Natl. Acad. Sci. USA 99: 1269112696

11. Stamler JS, Lamas S and Fang FC (2001) Nitrosylation. the prototypic redoxbased, signaling mechanism. Cell 106: 675-683

12. Ignarro LJ (1990) Haem-dependent activation of guanylate cyclase and cyclic GMP formation by endogenous nitric oxide: a unique transduction mechanism for transcellular signaling. Pharmacol. Toxicol. 67: 1-7
13. Hengartner MO (2000) The biochemistry of apoptosis. Nature 407: 770-776

14. Sarih M, Souvannavong V and Adam A (1993) Nitric oxide synthase induces macrophage death by apoptosis. Biochem. Biophys. Res. Commun. 191: 503508

15. Albina JE, Cui S, Mateo RB and Reichner JS (1993) Nitric oxide-mediated apoptosis in murine peritoneal macrophages. J. Immunol. 150: 5080-5085

16. Brune B, von Knethen A and Sandau KB (1999) Nitric oxide (NO): an effector of apoptosis. Cell Death Differ. 6: 969-975

17. Brune B, von Knethen A and Sandau KB (1998) Nitric oxide and its role in apoptosis. Eur. J. Pharmacol. 351: 261-272

18. Chung HT, Pae HO, Choi BM, Billiar TR and Kim YM (2001) Nitric oxide as a bioregulator of apoptosis. Biochem. Biophys. Res. Commun. 282: 1075-1079

19. Boyd CS and Cadenas E (2002) Nitric oxide and cell signaling pathways in mitochondrial-dependent apoptosis. Biol. Chem. 383: 411-423

20. Moncada S and Erusalimsky JD (2002) Does nitric oxide modulate mitochondrial energy generation and apoptosis? Nat. Rev. Mol. Cell. Biol. 3: 214-220

21. Bosca $L$ and Hortelano S (1999) Mechanisms of nitric oxide-dependent apoptosis: involvement of mitochondrial mediators. Cell Signal 11: 239-244

22. Borutaite V, Morkuniene R and Brown GC (2000) Nitric oxide donors, nitrosothiols and mitochondrial respiration inhibitors induce caspase activation by different mechanisms. FEBS Lett. 467: 155-159

23. Horn TF, Wolf G, Duffy S, Weiss S, Keilhoff G and MacVicar BA (2002) Nitric oxide promotes intracellular calcium release from mitochondria in striatal neurons. FASEB J. 16: 1611-1622

24. Yabuki M, Tsutsui K, Horton AA, Yoshioka T and Utsumi K (2000) Caspase activation and cytochrome $\mathrm{c}$ release during $\mathrm{HL}-60$ cell apoptosis induced by a nitric oxide donor. Free Radic. Res. 32: 507-514

25. Moriya R, Uehara T and Nomura $Y(2000)$ Mechanism of nitric oxide-induced apoptosis in human neuroblastoma SH-SY5Y cells. FEBS Lett. 484: 253-260

26. Bal-Price A and Brown GC (2000) Nitric-oxide-induced necrosis and apoptosis in PC12 cells mediated by mitochondria. J. Neurochem. 75: 1455-1464

27. Kim YM, Chung HT, Simmons RL and Billiar TR (2000) Cellular non-heme iron content is a determinant of nitric oxide-mediated apoptosis, necrosis, and caspase inhibition. J. Biol. Chem. 275: 10954-10961

28. Messmer UK, Ankarcrona M, Nicotera P and Brune B (1994) p53 expression in nitric oxide-induced apoptosis. FEBS Lett. 355: 23-26

29. Oyadomari S, Takeda K, Takiguchi M, Gotoh T, Matsumoto M, Wada I, Akira S, Araki $E$ and Mori M (2001) Nitric oxide-induced apoptosis in pancreatic beta cells is mediated by the endoplasmic reticulum stress pathway. Proc. Natl. Acad. Sci. USA 98: 10845-10850

30. Phoa $N$ and Epe $B$ (2002) Influence of nitric oxide on the generation and repair of oxidative DNA damage in mammalian cells. Carcinogenesis 23: 469-475

31. Davis DW, Weidner DA, Holian A and McConkey DJ (2000) Nitric oxidedependent activation of p53 suppresses bleomycin-induced apoptosis in the lung. J. Exp. Med. 192: 857-869

32. Tian B, Liu J, Bitterman PB and Bache RJ (2002) Mechanisms of cytokine induced NO-mediated cardiac fibroblast apoptosis. Am. J. Physiol. Heart. Circ. Physiol. 283: H1958-1967

33. Ishida A, Sasaguri T, Miwa Y, Kosaka C, Taba Y and Abumiya T (1999) Tumor suppressor p53 but not CGMP mediates NO-induced expression of p21(Waf1/Cip1/Sdi1) in vascular smooth muscle cells. Mol. Pharmacol. 56: 938-946

34. Yamaguchi A, Tamatani M, Matsuzaki H, Namikawa K, Kiyama H, Vitek MP, Mitsuda N and Tohyama M (2001) Akt activation protects hippocampal neurons from apoptosis by inhibiting transcriptional activity of p53. J. Biol. Chem. 276: 5256-5264

35. Li CQ, Trudel LJ and Wogan GN (2002) Nitric oxide-induced genotoxicity, mitochondrial damage and apoptosis in human lymphoblastoid cells expressing wild-type and mutant p53. Proc. Natl. Acad. Sci. USA 99: 10364-10369

36. Gordon SA, Abou-Jaoude W, Hoffman RA, McCarthy SA, Kim YM, Zhou X, Zhang XR, Simmons RL, Chen Y, Schall L and Ford HR (2001) Nitric oxide induces murine thymocyte apoptosis by oxidative injury and a p53-dependent mechanism. J. Leukoc. Biol. 70: 87-95

37. Kim SJ, Hwang SG, Shin DY, Kang SS and Chun JS (2002) p38 kinase regulates nitric oxide-induced apoptosis of articular chondrocytes by accumulating p53 via NFkappa B-dependent transcription and stabilization by serine 15 phosphorylation. J. Biol. Chem. 277: 33501-33508 
38. Nakaya N, Lowe SW, Taya Y, Chenchik A and Enikolopov G (2000) Specific pattern of p53 phosphorylation during nitric oxide-induced cell cycle arrest. Oncogene 19: 6369-6375

39. Wang X, Michael D, de Murcia G and Oren M (2002) p53 Activation by nitric oxide involves down-regulation of Mdm2. J. Biol. Chem. 277: 15697-15702

40. Hofseth LJ, Saito S, Hussain SP, Espey MG, Miranda KM, Araki Y, Jhappan C, Higashimoto Y, He P, Linke SP, Quezado MM, Zurer I, Rotter V, Wink DA Appella E and Harris CC (2003) Nitric oxide-induced cellular stress and p53 activation in chronic inflammation. Proc. Natl. Acad. Sci. USA 100: 143-148

41. Schneiderhan N, Budde A, Zhang $Y$ and Brüne $B$ (2003) Nitric oxide induces phosphorylation of p53 and impairs nuclear export. Oncogene (in press)

42. Shieh SY, Ikeda M, Taya Y and Prives C (1997) DNA damage-induced phosphorylation of p53 alleviates inhibition by MDM2. Cell 91: 325-334

43. Dumaz N and Meek DW (1999) Serine15 phosphorylation stimulates p53 transactivation but does not directly influence interaction with HDM2. EMBO J. 18: $7002-7010$

44. Zhang $Y$ and Xiong $Y$ (2001) A p53 amino-terminal nuclear export signa inhibited by DNA damage-induced phosphorylation. Science 292: 1910-1915

45. Haupt $Y$, Robles Al, Prives $C$ and Rotter V (2002) Deconstruction of p53 functions and regulation. Oncogene 21: 8223-8231

46. Taimor G, Rakow A and Piper HM (2001) Transcription activator protein 1 (AP1) mediates NO-induced apoptosis of adult cardiomyocytes. FASEB J. 15 2518-2520

47. Kim SJ, Ju JW, Oh CD, Yoon YM, Song WK, Kim JH, Yoo YJ, Bang OS, Kang SS, and Chun JS (2002) ERK-1/2 and p38 kinase oppositely regulate nitric oxide-induced apoptosis of chondrocytes in association with p53, caspase-3, and differentiation status. J. Biol. Chem. 277: 1332-1339

48. Kibbe MR, Li J, Nie S, Choi BM, Kovesdi I, Lizonova A, Billiar TR and Tzeng E (2002) Potentiation of nitric oxide-induced apoptosis in p53-/- vascular smooth muscle cells. Am. J. Physiol. Cell Physiol. 282: C625-634

49. Gu M, Lynch J and Brecher P (2000) Nitric oxide increases p21(Waf1/Cip1) expression by a cGMP-dependent pathway that includes activation of extracellular signal-regulated kinase and p70(S6k). J. Biol. Chem. 275: 11389-11396

50. Chae HJ, So HS, Chae SW, Park JS, Kim MS, Oh JM, Chung YT, Yang SH, Jeong ET, Kim HM, Park RK and Kim HR (2001) Sodium nitroprusside induces apoptosis of $\mathrm{H} 9 \mathrm{C} 2$ cardiac muscle cells in a c-Jun N-terminal kinase-dependent manner. Int. Immunopharmacol. 1: 967-978

51. Cheng A, Chan SL, Milhavet O, Wang S and Mattson MP (2001) p38 MAP kinase mediates nitric oxide-induced apoptosis of neural progenitor cells. J. Biol. Chem. 276: 43320-43327

52. Ghatan S, Larner S, Kinoshita Y, Hetman M, Patel L, Xia Z, Youle RJ and Morrison RS (2000) p38 MAP kinase mediates bax translocation in nitric oxideinduced apoptosis in neurons. J. Cell Biol. 150: 335-347

53. Kim SJ, Kim HG, Oh CD, Hwang SG, Song WK, Yoo YJ, Kang SS and Chun JS (2002) p38 kinase-dependent and -independent inhibition of protein kinase $C$ zeta and -alpha regulates nitric oxide-induced apoptosis and dedifferentiation of articular chondrocytes. J. Biol. Chem. 277: 30375-30381

54. Ibe W, Bartels W, Lindemann S, Grosser T, Buerke M, Boissel JP, Meyer J and Darius $\mathrm{H}$ (2001) Involvement of PKC and NF-kappaB in nitric oxide induced apoptosis in human coronary artery smooth muscle cells. Cell Physiol. Biochem. 11: 231-240

55. Tepperman BL, Chang Q and Soper BD (1999) The involvement of protein kinase $\mathrm{C}$ in nitric oxide-induced damage to rat isolated colonic mucosal cells. Br. J. Pharmacol. 128: 1268-1274

56. Gotoh T, Oyadomari S, Mori K and Mori M (2002) Nitric oxide-induced apoptosis in RAW 264.7 macrophages is mediated by endoplasmic reticulum stress pathway involving ATF6 and CHOP. J. Biol. Chem. 277: 12343-12350

57. Kawahara K, Oyadomari S, Gotoh T, Kohsaka S, Nakayama H and Mori M (2001) Induction of CHOP and apoptosis by nitric oxide in p53-deficient microglial cells. FEBS Lett. 506: 135-139

58. Liu L and Stamler JS (1999) NO: an inhibitor of cell death. Cell Death Differ. 6 937-942
59. Dimmeler S and Zeiher AM (1999) Nitric oxide-an endothelial cell survival factor. Cell Death Differ. 6: 964-968

60. Brune B and Mohr S (2001) Protein Thiol Modification of Glyceraldehyde-3phosphate Dehydrogenase and Caspase-3 by Nitric Oxide. Curr. Protein Pept. Sci. 2: 61-72

61. Dimmeler S, Haendeler J, Nehls M and Zeiher AM (1997) Suppression of apoptosis by nitric oxide via inhibition of interleukin-1beta-converting enzyme (ICE)-like and cysteine protease protein (CPP)-32-like proteases. J. Exp. Med. 185: 601-607

62. Melino G, Bernassola F, Knight RA, Corasaniti MT, Nistico G and Finazzi-Agro A (1997) S-nitrosylation regulates apoptosis. Nature 388: 432-433

63. Tenneti L, D'Emilia DM and Lipton SA (1997) Suppression of neuronal apoptosis by S-nitrosylation of caspases. Neurosci Lett. 236: 139-142

64. Mannick JB, Miao XQ and Stamler JS (1997) Nitric oxide inhibits Fas-induced apoptosis. J. Biol. Chem. 272: 24125-24128

65. Mohr S, Zech B, Lapetina EG and Brune B (1997) Inhibition of caspase-3 by Snitrosation and oxidation caused by nitric oxide. Biochem. Biophys. Res. Commun. 238: 387-391

66. Ogura T, Tatemichi M and Esumi H (1997) Nitric oxide inhibits CPP32-like activity under redox regulation. Biochem. Biophys. Res. Commun. 236: 365369

67. Li J, Billiar TR, Talanian RV and Kim YM (1997) Nitric oxide reversibly inhibits seven members of the caspase family via S-nitrosylation. Biochem. Biophys. Res. Commun. 240: 419-424

68. Kim YM, Talanian RV and Billiar TR (1997) Nitric oxide inhibits apoptosis by preventing increases in caspase-3-like activity via two distinct mechanisms. J. Biol. Chem. 272: 31138-31148

69. Rossig L, Fichtlscherer B, Breitschopf K, Haendeler J, Zeiher AM, Mulsch A and Dimmeler S (1999) Nitric oxide inhibits caspase-3 by S-nitrosation in vivo. J. Biol. Chem. 274: 6823-6826

70. Zech B, Wilm M, van Eldik R and Brune B (1999) Mass spectrometric analysis of nitric oxide-modified caspase-3. J. Biol. Chem. 274: 20931-20936

71. Klatt $P$ and Lamas $S(2000)$ Regulation of protein function by S-glutathiolation in response to oxidative and nitrosative stress. Eur. J. Biochem. 267: 49284944

72. Zech B, Kohl R, von Knethen A and Brune B (2003) Nitric oxide donors inhibit formation of the Apaf-1/caspase-9 apoptosome and activation of capases. Biochem. J. 371: 1055-1064

73. Mannick JB, Hausladen A, Liu L, Hess DT, Zeng M, Miao QX, Kane LS, Gow AJ, and Stamler JS (1999) Fas-induced caspase denitrosylation. Science 284 : 651-654

74. Hampton MB and Orrenius S (1997) Dual regulation of caspase activity by hydrogen peroxide: implications for apoptosis. FEBS Lett. 414: 552-556

75. Samali A, Nordgren H, Zhivotovsky B, Peterson E and Orrenius S (1999) A comparative study of apoptosis and necrosis in HepG2 cells: oxidant-induced caspase inactivation leads to necrosis. Biochem. Biophys. Res. Commun. 255: $6-11$

76. Li J, Bombeck CA, Yang S, Kim YM and Billiar TR (1999) Nitric oxide suppresses apoptosis via interrupting caspase activation and mitochondrial dysfunction in cultured hepatocytes. J. Biol. Chem. 274: 17325-17333

77. Torok NJ, Higuchi H, Bronk S and Gores GJ (2002) Nitric oxide inhibits apoptosis downstream of cytochrome $C$ release by nitrosylating caspase 9 . Cancer Res. 62: 1648-1653

78. Beere HM, Wolf BB, Cain K, Mosser DD, Mahboubi A, Kuwana T, Tailor $P$, Morimoto RI, Cohen GM and Green DR (2000) Heat-shock protein 70 inhibits apoptosis by preventing recruitment of procaspase-9 to the Apaf-1 apoptosome. Nat. Cell Biol. 2: 469-475

79. Saleh A, Srinivasula SM, Balkir L, Robbins PD and Alnemri ES (2000) Negative regulation of the Apaf-1 apoptosome by Hsp70. Nat. Cell Biol. 2: 476483

80. Bratton SB, MacFarlane M, Cain K and Cohen GM (2000) Protein complexes activate distinct caspase cascades in death receptor and stress-induced apoptosis. Exp. Cell Res. 256: 27-33 